\title{
In-vitro cytotoxic and anti-Vibrio cholerae activities of alcoholic extracts of Desmodium triflorum (L.) whole plant and Terminalia citrina (Roxb.) fruits
}

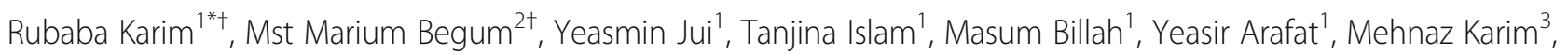
Ashfia Fatima Khan ${ }^{1}$ and Md. Sohanur Rahman ${ }^{4^{*}}$ (i)

\begin{abstract}
Background: The majority of epidemic Vibrio cholerae strains have become resistant to multiple antimicrobial agents for many reasons, including mutations, horizontal gene transfers, etc. Therefore, secondary means of treatment are needed to overcome this impediment in combating cholera. Desmodium triflorum (L.) and Terminalia citrina (Roxb.) are extensively used in traditional medicine. Therefore, the present study aims to evaluate the antibacterial activity of methanolic and ethanolic extracts of Desmodium triflorum (L.) whole plant and Terminalia citrina (Roxb.) fruits against $V$. cholerae isolates.
\end{abstract}

Methods: Initially, different extracts of both plant materials were subjected to qualitative phytochemical screening. Anti-V. cholerae activities were assessed by performing MIC (minimum inhibitory concentration) test using disc diffusion method with different concentrations $(1.25,2.50,8.00,10.00,12.50,15.00 \mathrm{mg} / \mathrm{ml})$ where standard discs of gentamycin and meropenem (10 $\mathrm{\mu g} / \mathrm{disc})$ were used. Further, Brine shrimp lethality bioassay was done to evaluate the extracts' cytotoxic activities using different concentrations $(800,400,200,100,50,25,12.5,6.25 \mu \mathrm{g} / \mathrm{ml})$ against vincristine sulphate.

Results: The preliminary screening confirms the presence of convenient phytochemical constituents like flavonoids, alkaloids, glycosides, tannins, etc., and are liable for the emergence of the antibacterial activities in different strains. The minimum inhibitory concentrations of both methanolic and ethanolic extracts of Terminalia citrina (fruits) and Desmodium triflorum (L.) (whole plant) were found to be $2.50 \mathrm{mg} / \mathrm{ml}$ and $5 \mathrm{mg} / \mathrm{ml}$, respectively. Moreover, $100 \%$ mortality was observed only in ethanolic extract of Terminalia citrina fruits at the highest concentration $(800 \mu \mathrm{g} / \mathrm{ml})$. In comparison, the rest of the test extracts showed less than $90 \%$ mortality at the highest concentration $(800 \mu \mathrm{g} / \mathrm{ml})$.

Conclusions: Both plants possess significant phytoconstituents and showed appreciable anti-V. cholerae activities with mild toxicity. Hence, Desmodium triflorum (L.) whole plant and Terminalia citrina (Roxb.) fruits may be recommended as potential phytotherapy against cholera disease.

Keywords: Vibrio cholerae, Cholera, Desmodium triflorum (L.), Terminalia citrina (Roxb.), Minimum inhibitory concentration (MIC), Zone of inhibition, Brine shrimp lethality assay (BSLA), Cytotoxicity

\footnotetext{
*Correspondence: rubkam.85@gmail.com; sohanbmb.ru@gmail.com

${ }^{\dagger}$ Rubaba Karim and Mst. Marium Begum contributed equally to this work.

'Department of Pharmacy, Primeasia University, Dhaka 1213, Bangladesh

${ }^{4}$ Department of Biochemistry and Molecular Biology, Trust University,

Barishal, Ruiya, Nobogram Road, Barishal 8200, Bangladesh

Full list of author information is available at the end of the article
}

\section{Springer Open}

(- The Author(s). 2021 Open Access This article is licensed under a Creative Commons Attribution 4.0 International License, which permits use, sharing, adaptation, distribution and reproduction in any medium or format, as long as you give appropriate credit to the original author(s) and the source, provide a link to the Creative Commons licence, and indicate if changes were made. The images or other third party material in this article are included in the article's Creative Commons licence, unless indicated otherwise in a credit line to the material. If material is not included in the article's Creative Commons licence and your intended use is not permitted by statutory regulation or exceeds the permitted use, you will need to obtain permission directly from the copyright holder. To view a copy of this licence, visit http://creativecommons.org/licenses/by/4.0/. 


\section{Background}

Cholera is recognized as an ancient diarrheal disease that is a continuous burden to public health for years in the developing and under-developed countries of Asia and Africa, where there are a population influx and poor water supply and basic hygiene. It is a water-borne bacterial disease caused by a facultative rod-shaped gram-negative anaerobic bacterium, $V$. cholerae. This bacterium is one of the most infamous enteric pathogens that belongs to the family Vibrionaceae [1]. The primary route of transmission of the bacterium to the human body is via the consumption of contaminated water and food. The bacterium attaches itself to the human small intestine. Eventually, it releases cholera toxins or choleragen, produced by $t c p$ gene of $V$. cholerae, which results in the production of the enzymatically active subunit that elevates intracellular cAMP (cyclic adenosine monophosphate), leading to accessive loss of water and electrolytes from the body via vomiting and severe form of acute secretory diarrhoea [2,3]. However, not all $V$. cholerae secret cholera toxins strains. There are only two causative strains of $V$. cholerae for the disease that belongs to the serogroups $\mathrm{O} 1$ and $\mathrm{O} 139$ and have been responsible for massive cholera pandemics for years [4]. The potential consequences of untreated cholera complications involve severe dehydration that may be fatal [5]. As a result, cholera is one of the leading causes of global mortality among infants, children under 5, and elderly individuals [6]. According to WHO (World Health Organization) report, every year, more than one million people suffering from acute diarrhoeal cases are caused by $V$. cholerae infection [7]. At present, the yearly global estimation of cholera cases is 2.9 million, including an annual death toll of around 95,000 [8]. Amongst the worldwide cholera cases, around 100,000 cases are found in Bangladesh, with about 4500 annual deaths [9]. Therefore, certain areas of Bangladesh significantly remain endemic for cholera [10]. For this reason, our country has been taking extensive measures to control and prevent the disease for the last few decades.

Antibiotics have been considered as the leading therapies for any kind of microbial infection. However, indiscriminate use of antibiotics may develop multi-drug resistant strains of microorganisms [11]. Nevertheless, many bacteria, including $V$. cholerae produce a biofilm under hostile conditions for which they show much resistance to antibiotics [12]. Besides, bacteria may develop antimicrobial drug resistance either by undergoing genetic mutation when exposed to antibiotics to treat epidemics or by the possession of resistance genes [13]. The latter is the case of $V$. cholerae resulting in its ability to resist certain antibiotics, including sulfamethoxazole, trimethoprim, chloramphenicol, and streptomycin [14]. Overall, the drug resistance to human pathogenic bacteria has been an alarming incidence throughout the world, raising constant demand to develop new and effective therapeutics [15]. Moreover, there is very little information about antibiotic susceptibility of environmental isolates of $V$. cholerae [16]. As a result, it is wise to acknowledge traditional medicine as an alternative option for treating infectious diseases as the herbal products are more economical and have fewer side-effects compared to synthetic drugs [17]. Many medicinal plants possess significant bioactive compounds that are potentially responsible for vibriocidal activities and hence recommended as promising sources of medicaments for cholera disease caused by several Vibrio spp. strains [3].

Different parts of the plant's Desmodium triflorum (L.) and Terminalia citrina (Roxb.) are used extensively to manage various diseases on a folklore basis. Desmodium triflorum (L.), commonly known as Jangali methi, belongs to the Fabaceae (papilonaceae) family and is available in all tropical countries, including the roadsides of Bangladesh [18]. The plant reportedly possesses antioxidant and anticonvulsant activity [19], analgesic, and anti-inflammatory activity [20], anthelmintic action [21], antibacterial, antidiarrheal, diuretic and anti-spasmodic activity [22], antipyretic [23], and anti-nociceptive activity [24]. On the other hand, Terminalia citrina ex Fleming (Bengali name: Haritaki) belongs to the family Combretaceae is wide-spread available throughout the forest areas of Bangladesh [25]. The plant leaves have antioxidant properties [25], while the fruit is traditionally used in long-term fever, loss of appetite, and as a sexual stimulant in Bangladesh [26]. In Iran, the plant is used in diarrhea, helminths, and other digestive disorders [27]. Both plants possess significant alkaloids and tannins that play a crucial role in antibacterial properties. Based on recent past reports, some potent alkaloids of Desmodium triflorum (L.), particularly indole-3-acetic acid and hypaphorine, showed an excellent score in molecular docking against few bacterial proteins of Gram-positive bacteria $(E$. coli) [28]. Conversely, literature data suggest that the methanolic extract of Terminalia citrine fruit yielded five known tannins identified as corilagin (1) (3), punicalagin (2) (4), 1,3,6-tri-O-galloyl- $ß-D$-glucopyranose (3) (5), chebulagic acid (4) (6), and 1,2,3,4,6-penta-O-galloyl- $\beta$-Dglucopyranose (5) (7) that exhibited antimicrobial activity against Escherichia coli, Staphylococcus aureus, Pseudomonas aeruginosa, Klebsiella pneumoniae, Candida albicans and Enterococcus spp. [29]. However, very few details about vibriocidal activities of these plants of Bangladesh has been reported in the literature. We aim to investigate anti- $V$. cholerae and cytotoxic activities of methanolic and ethanolic extracts of Desmodium triflorum (L.) whole plant concerning the above facts and Terminalia citrina (Roxb.) fruits. 


\section{Materials and methods Chemical reagents}

Standard antibiotic discs of Gentamycin and Meropenem were procured from the International Centre for Diarrhoeal Disease Research, Bangladesh (ICDDR, B). Müeller-Hinton agar (CMO337) was purchased from Oxoid, UK. Ethanol, methanol, tween 80 , and all other reagent materials were purchased from Merck (Darmstadt, Germany) and were of analytical grade. Brine shrimp eggs were obtained from the Bangladesh Fisheries Research Institute (BFRI) as a gift sample for the experimental work.

\section{Collection and preparation of plant material}

Desmodium triflorum (L.) whole plant and Terminalia citrina fruits were collected in mid-January 2019 from Jahangirnagar University, Dhaka, Bangladesh. The plant and fruits were identified and confirmed by a senior scientific officer of Bangladesh National Herbarium, Dhaka. A voucher specimen with Accession No: DACB 46482 and JUH 10507 for Terminalia citrina (Roxb.) and Desmodium triflorum $L$. respectively were deposited for future reference.

The whole extraction process was conducted in the Pharmacognosy \& Phytochemistry Laboratory of the Department of Pharmacy, Primeasia University, Dhaka, Bangladesh. The plant and fruits were washed thoroughly with clean water, cut into small pieces, and shade dried for 2 weeks. Coarse powder of plant and fruits was made with a knife mill $(0.86 \mu \mathrm{m})$. About $300 \mathrm{~g}$ and $150 \mathrm{~g}$ coarse dry powder of Terminalia citrina fruits and Desmodium triflorum $L$. whole plant were separately subjected to maceration process with 600 and $400 \mathrm{ml}$ alcohols (ethanol and methanol) respectively at $23^{\circ} \mathrm{C}$ for 21 days. Later, the mixtures were filtered using Whatman Filter paper No. 1, and the filtrates subsequently underwent distillation by employing a rotary evaporator (Buchi Rotavapor R-200, Germany) at $78.37^{\circ} \mathrm{C}$. The residual solvents were then allowed to dry out for a few days, and the final extracts were individually weighed and preserved in airtight containers. The percentage of yield of each extract were enumerated by using the following formula [30].

$$
\% \text { of yield }=\frac{\text { Weight of dried extract }(\mathrm{gm})}{\text { Weight of powdered crude plant }(\mathrm{gm})} \times 100
$$

\section{Preliminary phytochemical screening}

Medicinal plants are the potential sources of significant organic compounds like carbohydrates, alkaloids, tannins, triterpenoids, glycosides, flavonoids, steroids, essential oils, and their secondary metabolites, which exert definite biological or pharmacological actions on the human body [31]. Therefore, the present investigation was continued with a qualitative phytochemical screening of freshly prepared methanolic and ethanolic extract of Desmodium triflorum (L.) whole plant and Terminalia citrina fruits using standard protocols [32, 33].

\section{Bacterial strain and inoculum preparation}

The Microbiology Department of Primeasia University provided $V$. cholerae strain. The organism was immediately sub-cultured by transferring into a solid media of Müeller-Hinton agar slants under aseptic conditions followed by overnight incubation at $37^{\circ} \mathrm{C}$ to confirm bacterial colonies' growth. The inoculated plants were used for examining antibacterial activities of different alcoholic extracts of Desmodium triflorum (L.) whole plant and Terminalia citrina fruits against $V$. cholerae.

\section{Screening for anti-Vibrio cholerae activities of the test extracts}

Initial quantitative screening for anti- $V$. cholerae activities of plant and fruit extracts was performed by disc diffusion method described in a former work with a slight modification [34]. This was done by transferring one loopful of culture from the slants to separate test tubes containing $5 \mathrm{ml}$ sterile water, and the vortex eventually mixed the inoculums. About $100 \mu \mathrm{l}$ inoculum of the bacteria was evenly spread over a media of solid Müeller-Hinton agar set on four Petri dishes with the help of a sterile cotton swab. In due course, sterilized discs of Whatman filter paper of $8 \mathrm{~mm}$ in diameter were prepared by soaking with $40 \mu \mathrm{l}$ of ethanolic and methanolic extracts of Desmodium triflorum (L.) whole plant and Terminalia citrina fruits. The final concentration of each disc was $8 \mathrm{mg} / \mathrm{ml}$. For better precession, each crude extract was tested with four discs placed on the agar medium and pressed softly by employing sterile forceps. Standard antibiotic discs of Gentamycin and Meropenem with the strength of $10 \mu \mathrm{g} / \mathrm{disc}$ were represented as the positive control. The Petri dishes were then incubated for $24 \mathrm{~h}$ at $37^{\circ} \mathrm{C}$ to let the colonies of $V$. cholerae evolve.

The organism's susceptibility towards various test extracts was interpreted by determining the diameter of the zone of inhibition around each disc with Vernier caliper's help. This method was based on previously published interpretative criteria [35].

\section{Minimum inhibitory concentration (MIC) assay}

The standard disc diffusion procedure was followed to determine the minimum inhibitory concentration of different test extracts against $V$. cholerae [36]. The bacteria colonies were collected from the subculture media and emulsified with $5 \mathrm{ml}$ sterile water followed by vortex for $30 \mathrm{~s}$. Subsequently, $1 \mathrm{ml}$ of the inoculum was transferred 
and streaked using a sterile cotton swab into $150 \mathrm{~mm}$ culture plates holding $5 \mathrm{~mm}$ of Mueller-Hinton agar with a pH adjusted to 7.4. The plates were sterilized and individually labeled for each test extracts before the experiment. Paper discs ( $8 \mathrm{~mm}$ in diameter) of different concentrations of the test extracts $(1.25,2.50,8.00$, $10.00,12.50,15.00 \mathrm{mg} / \mathrm{ml}$ ) were prepared by diluting the crude extracts of Desmodium triflorum (L.) with $0.2 \%$ Tween 80 and Terminalia citrina with distilled water. The discs were then applied and pressed gently on the culture plates using sterilized forceps.

Next, the plates were subjected to incubation for $24 \mathrm{~h}$ at $37^{\circ} \mathrm{C}$. After incubation, the zones of inhibition formed around each disc were estimated on the culture plates' underside with the Vernier scale. All experimental tasks were performed under aseptic conditions.

\section{Brine shrimp lethality assay (BSLA)}

Some herbal medicines use crude plant extracts containing diverse bioactive molecules with unspecified pharmacological actions [37]. Many researchers preferably conduct toxicity tests to enrich the scientific data and rational utilization of significant medicinal plants [38]. The Brine shrimp lethality test is a simple and useful benchtop method that has been considered a general bioassay for detecting wide-ranging bioactivity of natural compounds in medicinal plants and indicating the general toxicity level crude plant extracts [39]. The method is rapid, inexpensive, and easy to perform as it utilizes simple zoological organisms (Brine nauplii).

For the present work, the in-vitro cytotoxicity study of different crude plant extracts was done by applying Brine shrimp lethality bioassay based on a published protocol with a slight modification [40]. Artificial seawater was prepared by dissolving $38 \mathrm{~g}$ iodine-less sea salt in 11 distilled water followed by filtration and filtrate collection into a large plastic container. The brine shrimp eggs were hatched in the artificial seawater with sufficient UV and oxygen supply for 2 days allowing them to thrive as nauplii. The test extracts were serial diluted with seawater to different concentrations (800, $400,200,100,50,25,12.5,6.25 \mu \mathrm{g} / \mathrm{ml}$ ) from a stock solution of $1600 \mu \mathrm{g} / \mathrm{ml}$. The stock was prepared by dissolving $32 \mathrm{mg}$ of crude extract in $200 \mu \mathrm{l} 0.2 \%$ Tween 80 , and the final volume was made up to $20 \mathrm{ml}$ with the addition of seawater. Finally, $2.5 \mathrm{ml}$ of test extract from each dilution was added to $2.5 \mathrm{ml}$ of seawater containing 10 nauplii in separate test tubes with a final volume of 5 $\mathrm{ml}$ and allowed to incubate under sufficient illumination at room temperature for $24 \mathrm{~h}$. After incubation, the total number of shrimp (nauplii) survived was recorded by viewing under a magnifying glass against a dark background. The experiment was done in a triplicate manner. The effect of cytotoxicity was assessed by determining $\mathrm{LC}_{50}$ (median lethal concentration or the concentration at which $50 \%$ mortality of brine shrimp nauplii occurred) values using regression analysis and percentage of mortality by applying the given formula.

$$
\text { Percentage mortality }(\% \mathrm{M})=\frac{\text { Number of dead nauplii }}{\text { Total number of nauplii }} \times 100
$$

The data was compared against different concentrations $(10,5,1,0.5,0.25,0.125$ and $0.06 \mu \mathrm{g} / \mathrm{ml})$ of vincristine solution as a standard control. The experiment was validated by considering a blank (negative control) containing $4.95 \mathrm{ml}$ seawater with 10 nauplii where $50 \mu \mathrm{l}$ of $0.2 \%$ Tween 80 was added.

\section{Data interpretation}

The experimental data were represented as mean \pm SEM (standard error mean) of four and three equivalent estimations for MIC (minimum inhibitory concentration) and cytotoxic assays. Regression analysis was done for assessing the values acquired from brine shrimp lethality bioassay.

\section{Results}

\section{Extraction yield of plant extracts}

The extractive values (\% of yield) and physical appearances of ethanolic and methanolic extracts of Desmodium triflorum (L.) whole plant and Terminalia citrina fruits have been represented in Table 1. Among the test samples, the maximum percentage $(7 \%)$ of the extract

Table 1 The extractive values and physical appearances of different test extracts

\begin{tabular}{llll}
\hline Sample & $\begin{array}{l}\text { Weight of crude } \\
\text { extract (gm) }\end{array}$ & \% of yield (w/w) & Appearance \\
\hline Methanolic extract of Terminalia citrine (fruit) & 12 & 4 & Deep brown with a citrus smell. \\
Methanolic extract of Desmodium triflorum (whole plant) & 8.2 & 5.5 & $\begin{array}{l}\text { Deep orange, muddy structure } \\
\text { with more consistency and stickiness. }\end{array}$ \\
Ethanolic extract of Terminalia citrine (fruit) & 15 & 5 & Deep brown with a citrus smell. \\
Ethanolic extract of Desmodium triflorum (whole plant) & 10.5 & Deep green, muddy structure with & less consistency. \\
\hline
\end{tabular}


Table 2 Presence of phytoconstituents in different test extracts

\begin{tabular}{lllll}
\hline Tests & Presence of constituents & & \\
\cline { 2 - 4 } & METC & EETC & + & MEDT \\
\hline Carbohydrate & + & + & + & + \\
Alkaloid & + & + & + \\
Glycoside & + & + & + \\
Tannins \& phenolic & + & + & - \\
Flavonoid & + & - & + \\
Terpenoid & - & + & - \\
Saponin & + & $*$ & + \\
Steroid & $*$ & & + \\
\hline
\end{tabular}

$(+)=$ present, $(-)=$ absent, $(*)=$ not detected

METC Methanolic extract of Terminalia citrina (Roxb.), EETC Ethanolic extract of Terminalia citrina (Roxb), MEDT Methanolic extract of Desmodium triflorum (L.), EEDT Ethanolic extract of Desmodium triflorum (L.)

was obtained from the crude powder of Desmodium triflorum (L.) whole plant with ethanol. Besides, ethanol aided in yielding adequate extracts of both plant materials. The extracts appeared to be of different colors and consistency.

\section{Evaluation of phytochemical content}

Preliminary phytochemical screening for different extracts of Desmodium triflorum (L.) whole plant and Terminalia citrina fruits revealed significant bioactive constituents, including alkaloid, glycosides, tannins, phenols, flavonoid, saponin, and carbohydrates (Table 2).

\section{Determination of anti-Vibrio cholerae activities}

Primary screening for antibacterial activities of different test extracts with $8 \mathrm{mg} / \mathrm{ml}$ potency was performed against $V$. cholerae. Various degrees of the zone of inhibition was observed in different samples compared with standard disks of antibiotics, including gentamycin and meropenem with a strength of $10 \mu \mathrm{g} /$ disk (Table 3). In a recent study, the strains of $V$. cholerae were reported to be well susceptible to several antibiotics, including meropenem, gentamycin, ciprofloxacin, chloramphenicol, azithromycin, etc. [41]. A similar observation was obtained in the present investigation for the antibiotics, meropenem, and gentamycin. V. cholerae was found to be susceptible to all test extracts of the same potencies.
However, the highest inhibitory zone of diameter $(13.75 \pm$ $1.65 \mathrm{~mm}$ ) was exhibited by the methanolic extract of Terminalia citrina fruits, which corresponded to standard meropenem data.

\section{Analysis of MIC assay}

The MIC (minimum inhibitory concentration) data showing inhibitory zones of growth for different extracts are represented in Table 4 . Variation in anti- $V$. cholerae activities of distinguished samples has been noted in our experiment. The organism showed no sensitivity to any extract at the lowest concentration $(1.25 \mathrm{mg} / \mathrm{ml})$. Nevertheless, the minimum inhibitory concentration of 2.50 $\mathrm{mg} / \mathrm{ml}$ was reported for methanolic and ethanolic extracts of Terminalia citrina fruits showing clear zones of inhibition of $8.30 \pm 0.36$ and $9.60 \pm 0.29 \mathrm{~mm}$, respectively ( Fig. 1). On the other hand, a little higher concentration $(5 \mathrm{mg} / \mathrm{ml})$ was seen to be the minimum attentiveness for suppressing $V$. cholerae growth in cases of methanolic and ethanolic extracts of Desmodium triflorum (L.) whole plant (Fig. 2), (Table 4).

\section{Assessment of cytotoxic activity}

The percentage of brine shrimp nauplii mortality was observed to be directly proportional to the concentrations of test extracts (Table 5). 100\% mortality was found in the ethanolic extract of Terminalia

Table 3 Antimicrobial screening test of ethanolic and methanolic extracts of different plants $(8 \mathrm{mg} / \mathrm{ml}, 40 \mu \mathrm{l} /$ disk) against Vibrio. cholerae

\begin{tabular}{|c|c|c|c|c|c|}
\hline \multicolumn{2}{|l|}{$\begin{array}{l}\text { Antibiotics } \\
(10 \mu \mathrm{g} / \text { disk })\end{array}$} & \multicolumn{4}{|l|}{$\begin{array}{l}\text { Plant extracts } \\
(8 \mathrm{mg} / \mathrm{ml})\end{array}$} \\
\hline Gentamicin & Meropenem & METC & EETC & MEDT & EEDT \\
\hline $22.38 \pm 0.47$ & $12.44 \pm 0.66$ & $13.75 \pm 1.65^{\mathrm{a}^{(* *)} \mathrm{b}(\mathrm{n})}$ & $11.25 \pm 0.63^{\mathrm{a}(* *) b(\eta)}$ & $12.00 \pm 0.27^{\mathrm{a}^{(* *)} \mathrm{b}(\eta)}$ & $11.25 \pm 0.63^{\mathrm{a}^{\mathrm{a} * *) \mathrm{b}(\eta)}}$ \\
\hline
\end{tabular}

Data represented as mean \pm SEM $(n=4)$

SEM standard error mean, $n$ number of sample, METC Methanolic extract of Terminalia citrina (Roxb.), EETC Ethanolic extract of Terminalia citrina (Roxb), MEDT Methanolic extract of Desmodium triflorum (L.), EEDT Ethanolic extract of Desmodium triflorum (L.)

${ }^{* *} p<0.01$ indicates Dunnett's multiple comparison test. $\mathrm{a}=$ when compared with Gentamicin, $\mathrm{b}=$ when compared with Meropenem. ( $\eta$ ) indicates statistically no significant difference from Meropenem 
Table 4 Zone of inhibition in diameter $(\mathrm{mm})$ of different alcoholic extracts of Terminalia citrina (Roxb.) fruits and Desmodium triflorum (L.) whole plant

\begin{tabular}{|c|c|c|c|c|c|c|c|}
\hline \multirow[t]{2}{*}{ Extracts } & \multicolumn{7}{|c|}{ Concentrations (mg/ml) (diameter: $\mathrm{mm}$ ) } \\
\hline & 1.25 & 2.50 & 5.00 & 8.00 & 10.00 & 12.50 & 15.00 \\
\hline METC & $0.00 \pm 0.00$ & $8.30 \pm 0.36$ & $12.75 \pm 1.32$ & $13.75 \pm 1.65$ & $17.00 \pm 0.41$ & $22.75 \pm 0.85$ & $24.25 \pm 0.48$ \\
\hline EETC & $0.00 \pm 0.00$ & $9.60 \pm 0.29$ & $10.75 \pm 0.48$ & $11.25 \pm 0.63$ & $13.75 \pm 0.63$ & $22.00 \pm 1.23$ & $30.00 \pm 0.56$ \\
\hline MEDT & $0.00 \pm 0.00$ & $0.00 \pm 0.00$ & $5.00 \pm 0.15$ & $12.00 \pm 0.27$ & $13.50 \pm 0.29$ & $15.30 \pm 0.35$ & $19.80 \pm 0.48$ \\
\hline EEDT & $0.00 \pm 0.00$ & $0.00 \pm 0.00$ & $2.50 \pm 0.35$ & $11.25 \pm 0.63$ & $13.25 \pm 0.63$ & $14.00 \pm 0.36$ & $16.40 \pm 0.24$ \\
\hline
\end{tabular}

Data represented as mean \pm SEM $(n=4)$

SEM standard error mean, $n$ number of sample, $\mathrm{mm}$ represent as Millimeter, METC Methanolic extract of Terminalia citrina (Roxb.), EETC Ethanolic extract of Terminalia citrina (Roxb), MEDT Methanolic extract of Desmodium triflorum (L.), EEDT Ethanolic extract of Desmodium triflorum (L.)

citrina fruits at its highest concentration $(800 \mu \mathrm{g} / \mathrm{ml})$. A similar observation was made for the case of vincristine sulphate. The lowest lethality concentration $\left(\mathrm{LC}_{50}\right)$ was appeared to be made by methanolic extract of Terminalia citrina fruits $(29.30 \mu \mathrm{g} / \mathrm{ml})$, showing a result much higher than the standard vincristine sulphate $(0.48 \mu \mathrm{g} / \mathrm{ml})$. As no mortality was seen in the negative control group, the test was valid, and the data drawn from the experiment were only due to test agents' effect. The regression equations are given in Table 6 and were obtained for each sample by plotting log concentration versus percentage mortality for all test samples showing a nearly linear correlation (Fig. 3). The alcoholic extracts of Terminalia citrina fruits displayed linear mortality rates (\%) with concentrations (Fig. 3b \& c). On the contrary, ethanolic extract of Desmodium triflorum (L.) showed steady mortality rates at lower and linear rates at higher concentrations. However, the opposite observation was made for the same plant's methanolic extract (Fig. 3d \& e).

\section{Discussion}

For many years, the growing demand for alternative medicine has led scientists to conduct potential research on plant materials. Plants possess many natural compounds with antimicrobial properties, including tannins, alkaloids, flavonoids, and terpenoids [42]. As a result, the herbal source's antibacterial compounds could be an economical and efficient therapeutic to cure and prevent bacterial infections with a minimal side effect. In Bangladesh, cholera is one of the most detrimental diseases that lead to fatality. Based on a recent survey, out of 160 million populations of our country, at least 66 million require protection against cholera due to the emergence of antibiotic-resistant Vibrio species [8].

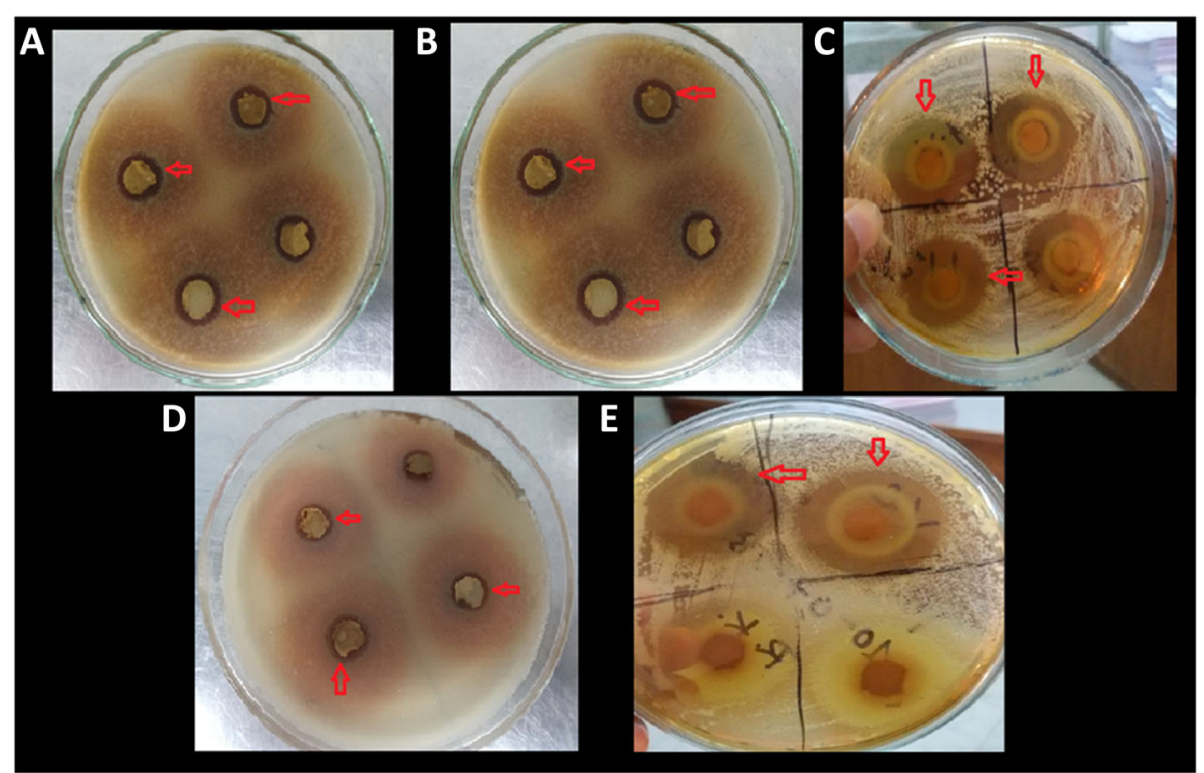

Fig. 1 Images of MIC (minimum inhibitory concentration) test. a, b \& c were 2.5, 5, and $15 \mathrm{mg} / \mathrm{ml}$ of ethanolic extracts of Terminalia citrina (Roxb.) fruits. $\mathbf{d}$ \& e were 5 and $15 \mathrm{mg} / \mathrm{ml}$ of methanolic extracts of Terminalia citrina (Roxb.) fruits. Each sample was replicated as $\mathrm{n}=4$. The zone of inhibition is indicated in the red arrow 


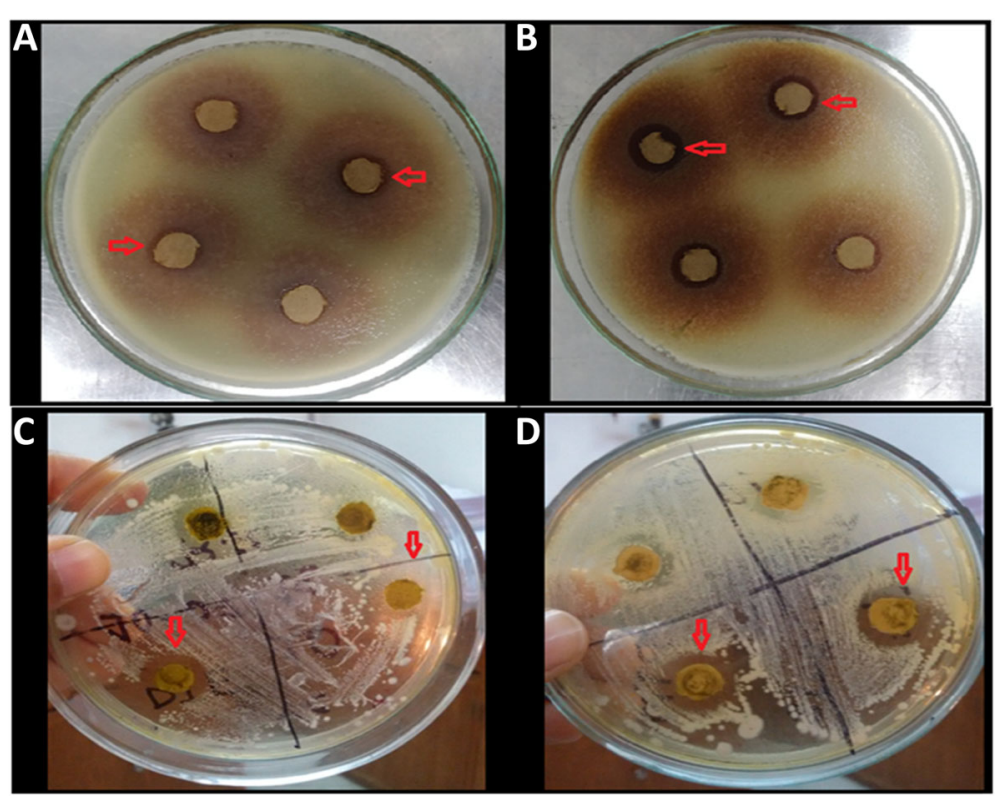

Fig. 2 Images of MIC (minimum inhibitory concentration) test. a \& b were $5 \mathrm{mg} / \mathrm{ml}$ of methanolic and ethanolic extracts of Desmodium triflorum (L.). $\mathbf{c} \& \mathbf{d}$ were $15 \mathrm{mg} / \mathrm{ml}$ of methanolic and ethanolic extracts of Desmodium triflorum (L.). Each sample was replicated as $n=4$. The zone of inhibition is indicated in the red arrow

Therefore, the present work focused on natural compounds from different plant sources, Desmodium triflorum (L.) whole plant and Terminalia citrina (Roxb.) fruits, which particularly reported for the presence of several tannins and alkaloids [28, 29]. The methanolic and ethanolic extracts of these plants confirmed bioactive compounds, including tannins, alkaloids, saponins, flavonoids, phenols, etc., on phytochemical screening present experiments.

In the current experiment, the in-vitro analysis for anti- $V$. cholerae activities of these plant sources revealed that $V$. cholerae is susceptible to alcoholic extracts of both Desmodium triflorum (L.) whole plant and Terminalia citrina (Roxb.) fruits that showed a zone of inhibition similar to that of the commercially available antibiotic (meropenem, $10 \mu \mathrm{g} /$ disk). Our results evidenced that different extracts' degree of hindering bacterial growth was done in a concentration-dependent manner. The minimum concentrations that inhibited the growth of $V$. cholerae were $2.50 \mathrm{mg} / \mathrm{ml}$ and $5.00 \mathrm{mg} / \mathrm{ml}$ for the alcoholic extracts of Terminalia citrina (Roxb.) fruits and Desmodium triflorum (L.) whole plant, respectively. Hence, our study indicated that the organism is more susceptible to ethanolic and methanolic extracts of Terminalia citrina (Roxb.) fruits than Desmodium triflorum (L.) whole plant. Besides, the magnitude of the zone of inhibition for ethanolic extract of Terminalia citrina (Roxb.) fruits at $15 \mathrm{mg} / \mathrm{ml}(30.00 \pm 0.56)$ was

Table 5 The percentage mortality of brine shrimp nauplii after treating with different concentrations of test extracts ( $n=3$ ) and the standard vincristine sulphate

\begin{tabular}{|c|c|c|c|c|c|c|c|c|}
\hline \multirow[t]{2}{*}{ Conc. $(\mu \mathrm{g} / \mathrm{ml})$} & \multirow[t]{2}{*}{$\log C$} & \multicolumn{4}{|c|}{$\%$ Mortality of test extracts } & \multicolumn{3}{|c|}{ Vincristine sulphate } \\
\hline & & MEDT & EEDT & METC & $\overline{\text { EETC }}$ & Conc. $(\mu \mathrm{g} / \mathrm{ml})$ & $\log C$ & $\%$ mortality \\
\hline 6.25 & 0.80 & 10 & 10 & 10 & 10 & 0.06 & -1.22 & 10 \\
\hline 12.5 & 1.10 & 30 & 10 & 30 & 20 & 0.125 & -0.90 & 10 \\
\hline 25 & 1.40 & 40 & 10 & 50 & 40 & 0.25 & -0.60 & 40 \\
\hline 50 & 1.70 & 50 & 20 & 60 & 40 & 0.5 & -0.30 & 60 \\
\hline 100 & 2.00 & 60 & 30 & 70 & 60 & 1 & 0.00 & 70 \\
\hline 200 & 2.30 & 60 & 40 & 80 & 60 & 5 & 0.70 & 100 \\
\hline 400 & 2.60 & 60 & 60 & 80 & 90 & 10 & 1.00 & 100 \\
\hline 800 & 2.90 & 80 & 80 & 90 & 100 & & & \\
\hline
\end{tabular}

METC Methanolic extract of Terminalia citrina (Roxb.), EETC Ethanolic extract of Terminalia citrina (Roxb), MEDT Methanolic extract of Desmodium triflorum (L.), EEDT Ethanolic extract of Desmodium triflorum (L.), $n$ number of sample 
Table 6 Values of $L C_{50}$ and regression equations for different test extracts

\begin{tabular}{llll}
\hline Sample & $\mathbf{L C}_{\mathbf{5 0}}(\boldsymbol{\mu \mathbf { g }} / \mathbf{m l})$ & Regression equation & $\mathbf{R}^{\mathbf{2}}$ \\
\hline MEDT & 34.50 & $y=28.078 x-3.18$ & 0.913 \\
EEDT & 118.93 & $y=33.22 x-28.94$ & 0.884 \\
METC & 29.30 & $y=35.99 x-7.81$ & 0.932 \\
EETC & 61.64 & $y=41.92 x-25.03$ & 0.962 \\
VS & 0.48 & $y=45.16 x+64.29$ & 0.950 \\
\hline
\end{tabular}

METC Methanolic extract of Terminalia citrina (Roxb.), EETC Ethanolic extract of Terminalia citrina (Roxb), MEDT Methanolic extract of Desmodium triflorum (L.), EEDT Ethanolic extract of Desmodium triflorum (L.), VS Vincristine sulphate, $L C_{50}$ Lethal concentration $50, R^{2}$ Coefficient of determination higher than that of gentamicin $(22.38 \pm 0.47)$. Therefore, our work suggests that the existing tannins, which reported to hold antimicrobial properties in the fruits of Terminalia citrina (Roxb.) are much potent against $V$. cholerae. However, an earlier report confirmed that the leaves of Terminalia citrina (Roxb.) do not possess any antimicrobial properties due to the low concentration of bioactive compounds within its leaf extract [25].

The cytotoxic potential of all samples was less than vincristine sulphate, indicating that both plants' crude extracts are safe for ethnopharmacological use with low toxicity. Nevertheless, the highest mortality rate and lowest $\mathrm{LC}_{50}$ value was found with alcoholic extracts of Terminalia citrina (Roxb.) fruits indicating a better cytotoxic profile than any other samples. Moreover, previous studies confirmed that the leaves of Terminalia citrina
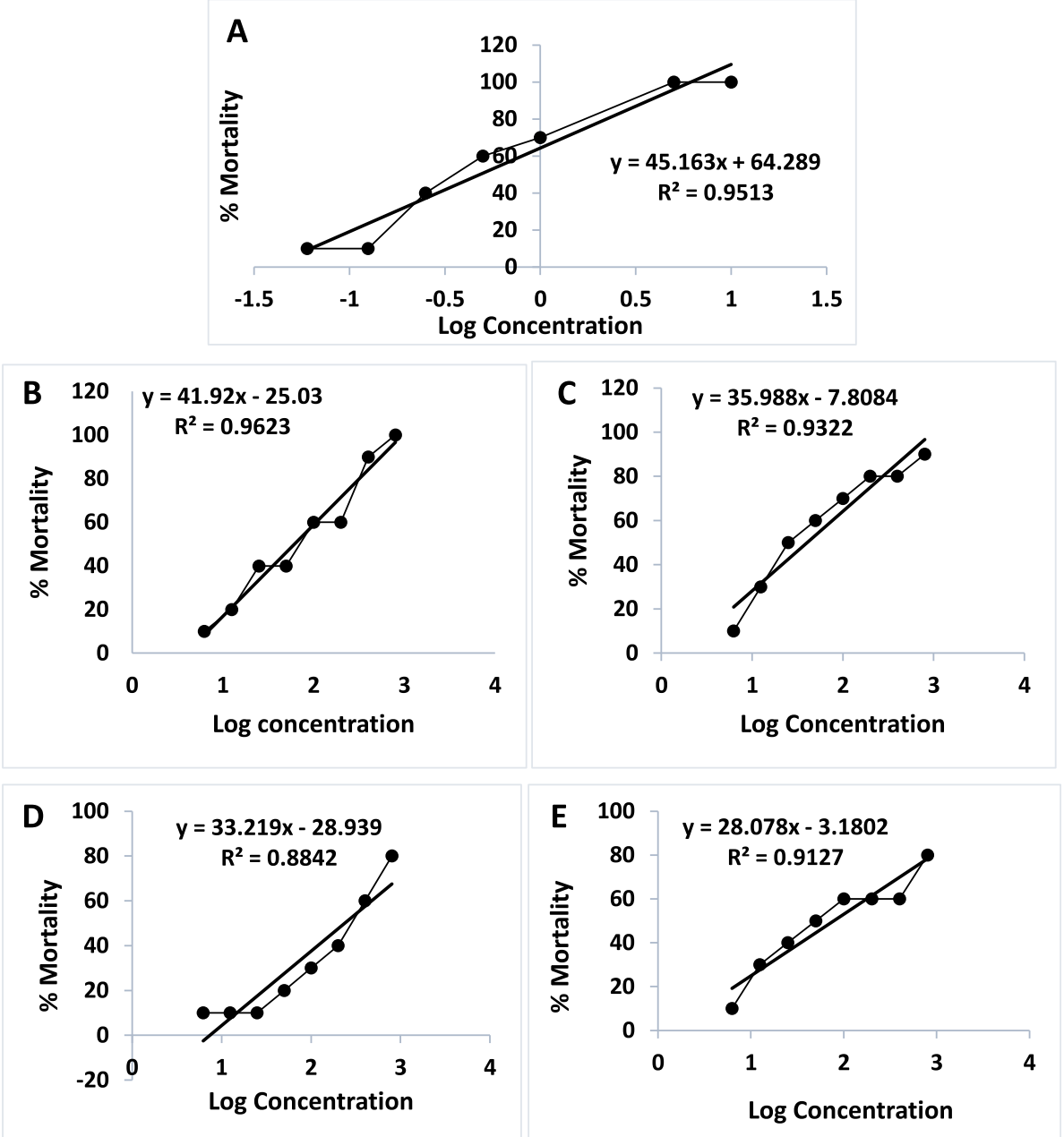

Fig. 3 Effect of test extracts $(n=3)$ at different concentrations (in logarithm) on mortality rate (\%) of brine shrimp nauplii. a Vincristine sulphate, $\mathbf{b}$ Ethanolic extract of Terminalia citrine (Roxb.), c Methanolic extract of Terminalia citrine (Roxb.), d Ethanolic extract of Desmodium triflorum (L.), e Methanolic extract of Desmodium triflorum (L.). $n=$ number of sample. $y=$ dependent variable (\% mortality), $x=$ independent variable (log concentration), $R^{2}=$ Coefficient of determination representing how close the data (dependent and independent variables) are to the fitted regression line; a value close to 100\% (1.00) is recognized as best fitted line (linear relationship between dependent and independent variables) 
(Roxb.) have weak cytotoxic properties [25], while the fruits exhibited significant cytotoxicity in human cancer cell lines [43]. Conversely, crude extract of Desmodium triflorum (L.) reported possessing low toxicity [44]. The toxicity effect of crude plant extract is assessed based on $\mathrm{LC}_{50}$ value where a value less than $1000 \mu \mathrm{g} / \mathrm{ml}$ is considered toxic, confirming the existence of bioactive compounds [45]. Thus, our investigation suggests that crude extracts of Desmodium triflorum (L.) whole plant and Terminalia citrina (Roxb.) fruits contain active or potent compounds that may exert significant pharmacological activities.

\section{Conclusion}

In conclusion, our study confirmed that the alcoholic extracts of Desmodium triflorum (L.) whole plant and Terminalia citrina (Roxb.) fruits have potential anti- $V$. cholerae activities, with mild toxicity, due to the presence of reported tannins and alkaloids. This indicates that the plant materials, Desmodium triflorum (L.) whole plant, and Terminalia citrina (Roxb.) fruits, may be used as reliable sources of herbal remedy against cholera disease in Bangladesh. Nonetheless, additional $V$. cholerae investigations of vibriocidal activities by specific tannins and alkaloids of these plant materials against the toxic strains of $V$. cholerae are needed.

\section{Abbreviations}

MIC: Minimum inhibitory concentration; BSLA: Brine shrimp lethality assay; $L C_{50}$ : Median lethal concentration at which $50 \%$ mortality observed; SEM: Standard error mean; METC: Methanolic extract of Terminalia citrina (Roxb.); EETC: Ethanolic extract of Terminalia citrina (Roxb.); MEDT: Methanolic extract of Desmodium triflorum (L.); EEDT: Ethanolic extract of Desmodium triflorum (L.)

\section{Acknowledgments}

We acknowledge the Department of Pharmacy, Primeasia University, Dhaka, Bangladesh, and Phytochemical Laboratory of the University of Dhaka, Dhaka, and Bangladesh to provide necessary research facilities and laboratory support. We also acknowledge the Department of Microbiology, Primeasia University, Dhaka, Bangladesh, for their kind donation of bacterial isolates. A special thanks to Prof. Dr. Zahed Uddin Mahmood Khan (Department of Botany, Jahangirnagar University) for his scientific assistance to conduct this research.

\section{Authors' contributions}

RK made significant contributions to construct and conduct the experiment. YJ, TI, MB, and YA performed all experimental tasks in the laboratory. MK and MMB made data collection, statistical analysis, and interpretation. RK and MSR wrote the article. AFK and MSR did the critical revision of the article. Finally, MSR revised and submitted the article. RK and MMB exhibited the same contribution, and RK and MSR share the correspondence equally. All Authors read and approved the final manuscript.

\section{Funding}

No funding sources.

\section{Declarations}

\section{Consent for publication}

We confirm that this manuscript has not been published elsewhere and is not under consideration by another journal. All authors have approved the manuscript and agreed with submission.

\section{Competing interests}

The authors declare that they have no competing interests.

\section{Author details}

${ }^{1}$ Department of Pharmacy, Primeasia University, Dhaka 1213, Bangladesh. ${ }^{2}$ Department of Pharmacy, East West University, Aftabnagar, Dhaka 1212, Bangladesh. ${ }^{3}$ Department of Mathematics and Natural Sciences, BRAC University, Dhaka 1212, Bangladesh. ${ }^{4}$ Department of Biochemistry and Molecular Biology, Trust University, Barishal, Ruiya, Nobogram Road, Barishal 8200, Bangladesh.

Received: 10 December 2020 Accepted: 1 April 2021

Published online: 12 April 2021

\section{References}

1. Nishibori T, de Vries GC, Rahardjo D, Wasito EB, De I, Kinoshita S, et al. Phenotypic and genotypic characterization of Vibrio cholerae clinically isolated in Surabaya, Indonesia. Jpn J Infect Dis. 2011;64(1):7-12.

2. Chakraborty S. Plant derived extracts and respective compounds against major life-threatening water contaminant bacteria Vibrio cholerae: a comprehensive mini review. Int Res J Environ Sci. 2015;4(7):96-105.

3. Aminzare $M$, Hashemi $M$, Abbasi $Z$, Mohseni $M$, Amiri E. Vibriosis phytotherapy: a review on the most important world medicinal plants effective on Vibrio spp. J App Pharm Sci. 2018:8(01):170-7.

4. Reidl J, Klose KE. Vibrio cholerae and cholera: out of the water and into the host. FEMS Microbiol Rev. 2002;26(2):125-39. https://doi.org/10.1111/j.15746976.2002.tb00605.x

5. Harris JB, Larocque RC, Qadri F, Ryan ET, Calderwood SB. Cholera. Lancet 2012;379(9835):2466-76. https://doi.org/10.1016/S0140-6736(12)60436-X.

6. Colombara DV, Cowgill KD, Faruque AS. Risk factors for severe cholera among children under five in rural and urban Bangladesh, 2000-2008: a hospital-based surveillance study. PLoS One. 2013;8(1):e54395 https://doi. org/10.1371/journal.pone.0054395.

7. Cholera annual report 2012. Wkly Epidemiol Rec. 2013;88(31):321-336

8. Islam MT, Clemens JD, Qadri F. Cholera control and prevention in Bangladesh: an evaluation of the situation and solutions. J Infect Dis. 2018; 218(Suppl 3):S171-2. https://doi.org/10.1093/infdis/jiy470.

9. Ali M, Nelson AR, Lopez AL, Sack DA. Updated global burden of cholera in endemic countries. PLoS Negl Trop Dis. 2015;9(6):e0003832. https://doi.org/1 0.1371/journal.pntd.0003832.

10. Saha A, Chowdhury MI, Khanam F, Bhuiyan MS, Chowdhury F, Khan Al, et al. Safety and immunogenicity study of a killed bivalent (O1 and O139) wholecell oral cholera vaccine Shanchol, in Bangladeshi adults and children as young as 1 year of age. Vaccine. 2011;29(46):8285-92. https://doi.org/10.101 6/j.vaccine.2011.08.108.

11. Ventola CL. The antibiotic resistance crisis: part 1: causes and threats. P T. 2015:40(4):277-83.

12. Lewis K. Riddle of biofilm resistance. Antimicrob Agents Chemother. 2001; 45(4):999-1007. https://doi.org/10.1128/AAC.45.4.999-1007.2001.

13. Baron S, Lesne J, Jouy E, Larvor E, Kempf I, Boncy J, et al. Antimicrobial susceptibility of autochthonous aquatic Vibrio cholerae in Haiti. Front Microbiol. 2016:7:1671. https://doi.org/10.3389/fmicb.2016.01671.

14. Hochhut B, Lotfi Y, Mazel D, Faruque SM, Woodgate R, Waldor MK. Molecular analysis of antibiotic resistance gene clusters in Vibrio cholerae 0139 and 01 SXT constins. Antimicrob Agents Chemother. 2001;45(11): 2991-3000. https://doi.org/10.1128/AAC.45.11.2991-3000.2001.

15. Monroe S, Polk R. Antimicrobial use and bacterial resistance. Curr Opin Microbiol. 2000;3(5):496-501. https://doi.org/10.1016/\$1369-5274(00)00129-6.

16. Zhang XY, Han XX, Chen XL, Dang HY, Xie BB, Qin QL, et al. Diversity of cultivable protease-producing bacteria in sediments of Jiaozhou Bay, China. Front Microbiol. 2015:6:1021.

17. Aminzare M, Aliakbarlu J, Tajik H. The effect of Cinnamomum zeylanicum essential oil on chemical characteristics of Lyoner-type sausage during refrigerated storage. Vet Res Forum. 2015;6(1):31-9. 
18. Kanhoba RK, Basu BD. Indian medicinal plants, vol. II. Dehradun: International Book Distributors; 1987. p. 1429.

19. Bhosle V. Anticonvulsant and antioxidant activity of aqueous leaves extract of Desmodium triflorum in mice against pentylenetetrazole and maximal electroshock induced convulsion. Rev Bras. 2013;23(4):692-8. https://doi. org/10.1590/S0102-695X2013005000047.

20. Chowdhury KK, Saha A, Bachar SC, Kundu JK. Analgesic and anti-inflammatory activities of Desmodium triflorum DC. J Biol Sci. 2005;5(5):581-3.

21. Raj RK. Screening of indigenous plants for anthelmintic action against human Ascaris lumbricoides. Indian J Physiol Pharmacol. 1974;18(2): 129-31.

22. Yoganarasimhan SN, Jadhav D. Medicinal plants of India. Interline Publ. 1996

23. Samvatsar S, Diwanji VB. Plants used for the treatment of different types of fevers by Bhils and its subtribes in India. Indian J Tradit Knowl. 2004;3(1):96-100.

24. Daya RW, Chandra JA, Dayendra RC. Antinociceptive activity of cold water extract of desmodium triflorum in rats. Int Res J Pharm. 2011;2(7):120-3.

25. Das N, Goshwami D, Hasan MS, Al Mahmud Z, Raihan SZ. Evaluation of antioxidant, antimicrobial and cytotoxic activities of terminalia citrina leaves. J Pharm Res. 2016;10(1):8-15.

26. Hossan MS, Hanif A, Khan M, Bari S, Jahan R, Rahmatullah M. Ethnobotanical survey of the Tripura tribe of Bangladesh. Am Eur J Sustain Agric. 2008;3(2):253-61.

27. Amiri MS, Joharchi MR. Ethnobotanical investigation of traditional medicinal plants commercialized in the markets of Mashhad, Iran. Avicenna J Phytomed. 2013;3(3):254-71.

28. Princy KR, Sripathi R, Dharani J, Ravi S. Molecular docking studies of alkaloids from Desmodium triflorum against bacterial proteins. J Pharm Sci Res. 2017; 9(10):1882-5.

29. Burapadaja S, Bunchoo A. Antimicrobial activity of tannins from Terminalia citrina. Planta Med. 1995;61(04):365-6. https://doi.org/10.1055/ s-2006-958103.

30. SS P, Jadhav MG, Deokar TG. Study of phytochemical screening, physicochemical analysis and antimicrobial activity of bacopamonnieri (L) extracts. Int J Pharm Clin Res. 2016;8(8):1222-9.

31. Edeoga HO, Okwu DE, Mbaebie BO. Phytochemical constituents of some Nigerian medicinal plants. Afr J Biotechnol. 2005;4(7):685-8. https://doi.org/1 0.5897/AJB2005.000-3127.

32. Yadav M, Chatterji S, Gupta SK, Watal G. Preliminary phytochemical screening of six medicinal plants used in traditional medicine. Int J Pharm Pharm. 2014;6(5):539-42.

33. Tiwari $P$, Kumar B, Kaur M, Kaur G, Kaur H. Phytochemical screening and extraction: a review. Int Pharm Sci. 2011;1(1):98-106.

34. Bayer AW, Kirby WM, Sherris JC, Turck M. Antibiotic susceptibility testing by a standardized single disc method. Am J Clin Pathol. 1966;45(4):493-6. https://doi.org/10.1093/ajcp/45.4_ts.493.

35. Lino A, Deogracious O. The in-vitro antibacterial activity of Annona senegalensis, Securidacca longipendiculata and Steganotaenia araliaceaUgandan medicinal plants. Afr Health Sci. 2006;6(1):31-5. https://doi.org/10. 5555/afhs.2006.6.1.31.

36. Bauer AW, Kirby QMM, Sherris JC, Turck M. Antibiotic susceptibility testing by a standardized single disk method. Am J Clin Pathol. 1966;45(4):493-6. https://doi.org/10.1093/ajcp/45.4_ts.493.

37. Konan NA, Bacchi EM, Lincopan N, Varela SD, Varanda EA. Acute, subacute toxicity and genotoxic effect of a hydroethanolic extract of the cashew (Anacardium occidentale L.). J Ethnopharmacol. 2007;110(1):30-8. https:// doi.org/10.1016/j.jep.2006.08.033.

38. Badakhshan MP, Sasidharan S, Rameshwar NJ, Ramanathan S. A comparative study: antimicrobial activity of methanol extracts of Lantana camara various parts. Phcog Res. 2009;1(6):348-51.

39. Pisutthanan S, Plianbangchang P, Pisutthanan N, Ruanruay S, Muanrit O. Brine shrimp lethality activity of Thai medicinal plants in the family Meliaceae. Naresuan Univ J Sci Technol (NUJST). 2013;12(2):13-8.

40. Asaduzzaman M, Rana MS, Hasan SR, Islam R, Das N. Phytochemical and antioxidant investigation of barringtonia acutangula (L.). Eur J Med Plants. 2015;8(4):21:231-8.

41. Lu B, Zhou H, Li D, Li F, Zhu F, Cui Y, et al. The first case of bacteraemia due to non-01/non-0139 Vibrio cholerae in a type 2 diabetes mellitus patient in mainland China. Int J Infect Dis. 2014;25:116-8. https://doi.org/10.1016/j.ijid.2 014.04.015.
42. Cowan MM. Plant products as antimicrobial agents. Clin Microbiol Rev. 1999;12(4):564-82. https://doi.org/10.1128/CMR.12.4.564.

43. Sangthong P, Nittayajaiprom W, Chancharunee S, Wipatanawin A, Wanasawas P, Chulasiri M. Mutagenicity, antimutagenicity and tyrosinase inhibition activity of hydroglycol extracts from Terminalia chebula Retzius, Terminalia bellerica Roxb and Rafflesia kerrii Meijer. Int J Phytomedicine. 2014;6(1):93-102.

44. Lai SC, Ho YL, Huang SC, Huang TH, Lai ZR, Wu CR, et al. Antioxidant and antiproliferative activities of Desmodium triflorum (L.) DC. Am J Chin Med. 2010;38(02):329-42. https://doi.org/10.1142/S0192415X10007889.

45. Meyer BN, Ferrigni NR, Putnam JE, Jacobsen LB, Nichols DJ, McLaughlin JL. Brine shrimp: a convenient general bioassay for active plant constituents. Planta Med. 1982;45(5):31-4. https://doi.org/10.1055/s-2007-971236.

\section{Publisher's Note}

Springer Nature remains neutral with regard to jurisdictional claims in published maps and institutional affiliations.

\section{Submit your manuscript to a SpringerOpen ${ }^{\circ}$ journal and benefit from:}

- Convenient online submission

- Rigorous peer review

- Open access: articles freely available online

- High visibility within the field

- Retaining the copyright to your article

Submit your next manuscript at $\boldsymbol{\nabla}$ springeropen.com 